\title{
Stress Analysis of FRP Composite Cylinder with Closed Ends
}

\author{
C. Sasi Rekha ${ }^{1}$, P.RaviKumar ${ }^{2}$, K.VenkataRao $^{2}$ \\ ${ }^{1}$ M.TechStudent, P.V.P. Siddhartha Institute of Technology, Vijayawada, A.P, India \\ ${ }^{2}$ Asst. Professor, Mech.Engg.Dept.P.V.P.SiddharthaInstituteofTechnology, Vijayawada,A.P, India
}

\begin{abstract}
Composite cylinders made of a polymer matrix such as epoxy reinforced with glass or carbon fibers possess extremely high strength. Proper modeling of FRP composite cylinder is very essential for many applications. FRP composite cylinders are commonly used in the aerospace, automotive, marine and construction industries. The present work is to study the variation of stressesat the top end, middle and bottom end portions of a composite cylinder by varying the diameter to thickness ratio(S) and fiber angle ( $\theta$ ). The four layered angle ply $\left(\theta^{0} /-\theta^{0} /-\theta^{0} / \theta^{0}\right)$ composite cylinder is considered forthe present work and behavior of each portion (Top end, middle and Bottom end) is studied.For the present work composite cylinder is modeled in ANSYS and analysis was carried out using numerical software. It isfound thatthe increment of stress takes place linearly with respect to D/t ratio due to reduction in thickness of the layer. The critical fiber angle is $45^{\circ}$ to $60^{\circ}$ as it offers high resistance against axial and circumferential deformation in middle and end portions.
\end{abstract}

Keywords: Composite Cylinder, Lamina, Fiber Angle, FEM, ANSYS

\section{Introduction}

The development of advanced fiber reinforced composite cylinders has been considered as the biggest technical revolution after the jet engine. FRP composites possess high strength and stiffness. In addition fatigue strength to weight ratio as well as fatigue damage tolerance of many composite laminates is excellent. Coefficient of thermal expansion for many FRP composites is much lower than those of metals. As such composite structures exhibit a better dimensional stability over a wide range of temperature variation. Damage of composite structures is usually in nature and can be detected only by sophisticated nondestructive testing. Because of their low maintenance cost and light weight, many structures are nowadays made of FRP composites. Spacecraft may have weight savings as much as $40 \%$ if FRP composite structures are used. Therefore, the use of FRP composite materials is increasing compared to conventional materials. Adali et al [1] have derived three dimensional elastic conditions for axis symmetrical loading conditions for a multi-layered pressure vessel subjected to internal pressure. Roy and Tsai [2] found a simple design method for the stress analysis of a plane strain composite cylinder based on 3D elasticity. Starbuck [3] presented a closed form solution for the layer-by- layer stresses and strains based on the theory of anisotropic elasticity and plane deformation.Multi layered composite cylinders subjected to hygrothermal loading conditions were studied by Sayman [4]. Structural analysis of fiber reinforced pressure vessel have been investigated by Christos et al [5] for three different ply layers independently using computer code for simulation of damage and its growth due to internal pressure. Ahmadian and Bonakdar [6] investigated laminated hallow cylinders subjected to various loads and boundary conditions using 16 node cylindrical super element. Kranti [7] proved that a minimum of $100 \mathrm{~mm}$ length is required to study the behavior of infinitely long FRP composite cylinder. E.V. Morozov [8] investigated the behavior of a thin walled composite cylinder when subjected to 2, 4 and 8 unit filament wound and also conducted the stress analysis for the cylinder.Rani Haj Ali et al [9] combined micromechanical and cohesive finite element modeling approach to predict the failure of a FRP composite under Mode-I and Mode-II loading conditions. A micromechanical constitutive model was used to capture the non-linear material response. For thick section composites, a mixed mode fracture failure criterion was proposed. S. Bhavya [10] conducted the failure analysis of an open end FRP composite cylinder and has observed that the stresses increase and load bearing capacity of cylinder decreases withincrease in D/t Ratio. J. C. Velosa et al. [11] have studied composite pressure vessels for large scale market applications. These vessels consist on a thermoplastic liner wrapped with a filament winding glass fiber reinforced polymer matrix structure.

\section{Problem Statement}

Thepresentworkdealswiththe StressanalysisoftheFRP compositecylinder with closed ends. A four layered $\left(\theta^{0} /-\theta^{0} /-\theta^{0} / \theta^{0}\right)$ composite cylinder with semicircular ends is considered. A metal cap is provided in the ends for openings. The finite element models created in ANSYS software are validated and extended to evaluate the stresses at the top end, middle and bottom end portions of composite cylinder. 


\subsubsection{Geometric Modeling}

\section{Modeling Of The Problem}

The geometry of theproblemis:

Diameterofthecylinder $=100 \mathrm{~mm}$,

Thickness of thecylinder=Dia.Ofcylinder/S

(Where "S" is the diameter to thickness ratio whose value ranges from 5 to 100 )

Stacking Sequence $=\left(\theta^{0} /-\theta^{0} /-\theta^{0} / \theta^{0}\right)$

(Where " $\theta$ " is the fiber angle with respect to cylinder axis)

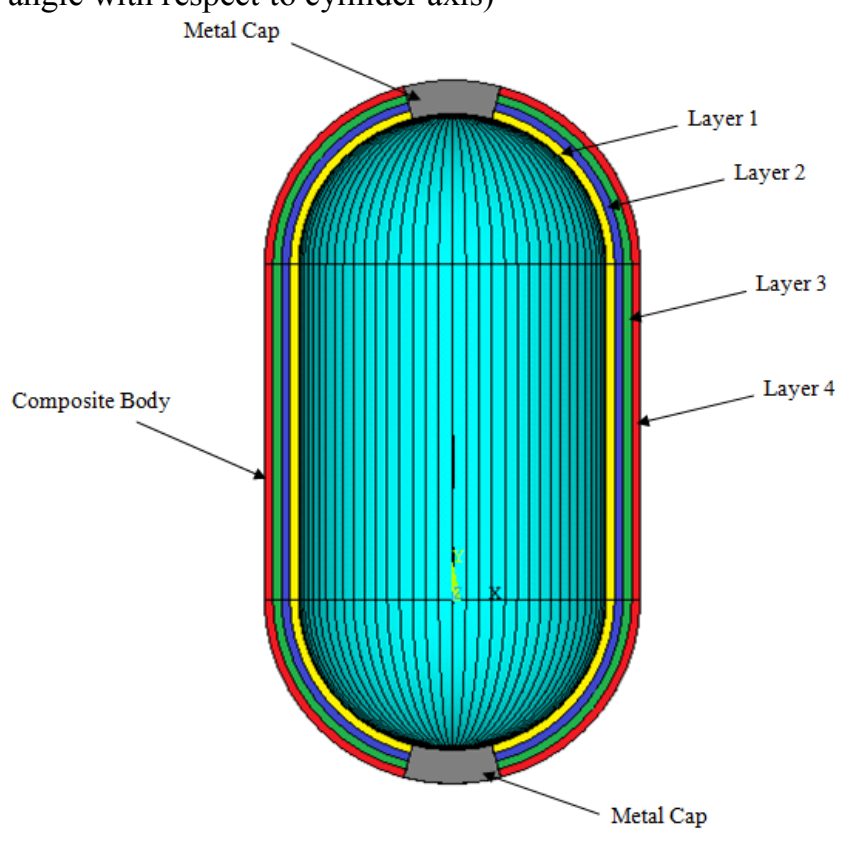

Fig 1. Composite Cylinder with four layers

\subsubsection{Finite Element Modeling}

Using ANSYS software the problem is modeled and the finite element model is generated using SOLID 191 element on four volumes corresponding to four layers of laminate structure. Solid 191 is a 20nodesecond order brick element having three degrees of freedom at each node and is suitable to incorporateorthotropic material properties. The finite element model is generated in ANSYS software for angleply laminate having stacking sequence of $\left(\theta^{0} /-\theta^{0} /-\theta^{0} / \theta^{0}\right)$. The mesh refinement is carried out until the radialstresses at inner and outer surfaces of the cylinder closely matches with applied pressure and zero respectively. A separate coordinate system has been provided at the top end and bottom end for the analysis of semicircular caps.

\subsubsection{Material Properties}

In the present work carbon epoxy with the following properties are adopted

\begin{tabular}{|c|c|c|}
\hline $\mathrm{E}_{1}=147 \mathrm{GPA}$ & $v_{12}=0.27$ & $\mathrm{G}_{12}=7 \mathrm{GPA}$ \\
\hline $\mathrm{E}_{2}=10.3 \mathrm{GPA}$ & $\mathrm{v}_{23}=0.54$ & $\mathrm{G}_{23}=3.7 \mathrm{GPA}$ \\
\hline $\mathrm{E}_{3}=10.3 \mathrm{GPA}$ & $v_{13}=0.27$ & $\mathrm{G}_{13}=7 \mathrm{GPA}$ \\
\hline
\end{tabular}

For Metal cap Steel with following properties are adopted $\mathrm{E}=2 \mathrm{e} 5 \mathrm{MPA}, v=0.3$

\subsubsection{Boundary conditions and Loads}

The symmetry line of the cylinder restricted to move in radial direction. Internal surface of the cylinder subjected to pressure of $1 \mathrm{MPa}$

\section{Validity of the Present Analysis}

Present finite element model is validated by verifying the radial, circumferential and axial stresses by applying isotropic material properties at middle location of the cylinder. It is observed that the finite element results are in close agreement with theoretical results. The theoretical results are obtained from lames equations. 


\begin{tabular}{|c|c|c|c|}
\hline & $\boldsymbol{\sigma}_{\mathbf{r}}$ & $\boldsymbol{\sigma}_{\mathbf{c}}$ & $\boldsymbol{\sigma}_{\mathbf{a}}$ \\
\hline Theoretical & -0.42525 & 4.47525 & 2.025 \\
\hline Ansys & -0.42145 & 4.5938 & 2.024 \\
\hline \% Error & 0.893592 & 2.64901 & 0.049383 \\
\hline
\end{tabular}

\section{Results and Discussions}

The finite element model is generated in ANSYS software and the stresses are obtained. The results are taken for the following two cases.

1. Analysis of cylinder with various $\mathrm{D} / \mathrm{t}$ ratio

2. Analysis of cylinder with various fiber angles.

\section{Effect of D/t Ratio}

The variation of radial stress with respect to Diameter to thickness ratio (S) is plotted as shown in the figure 2 for top end, middle and bottom end portions of a FRP composite cylinder. It is observed that at middle portion the radial stress almost remains constant and the maximum stress is observed in the end portions of the composite cylinder because of curvature and the value of the maximum radial stress is observed to be 1.62 MPA.

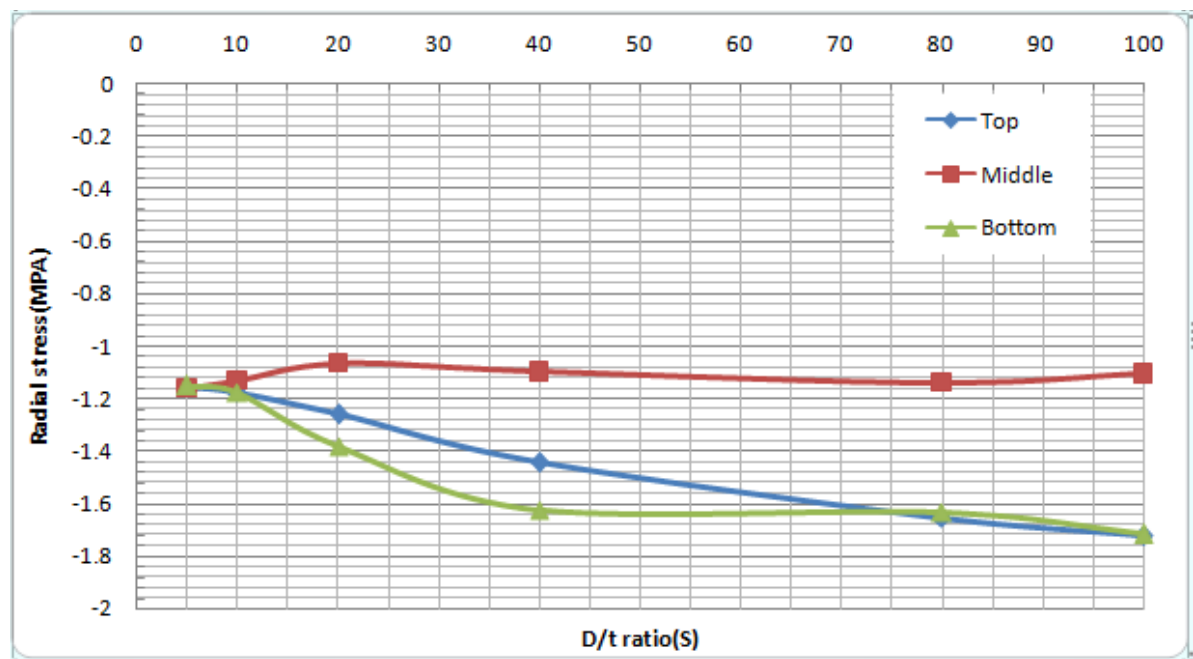

Fig 2.Variation of radial stress with respect to $\mathrm{D} / \mathrm{t}$ Ratio(S).

The variation of circumferential stress with respect to Diameter to thickness ratio (S) is plotted as shown in the figure 3 for top end, middle and bottom end portions of a FRP composite cylinder. It is observed that circumferential increases linearly in all the three portions with increase in the $\mathrm{d} / \mathrm{t}$ ratio. The maximum stress is observed in the top and bottom portions whose value is equal to 60MPA. The increase in stress takes place due to reduction in thickness of the layer.

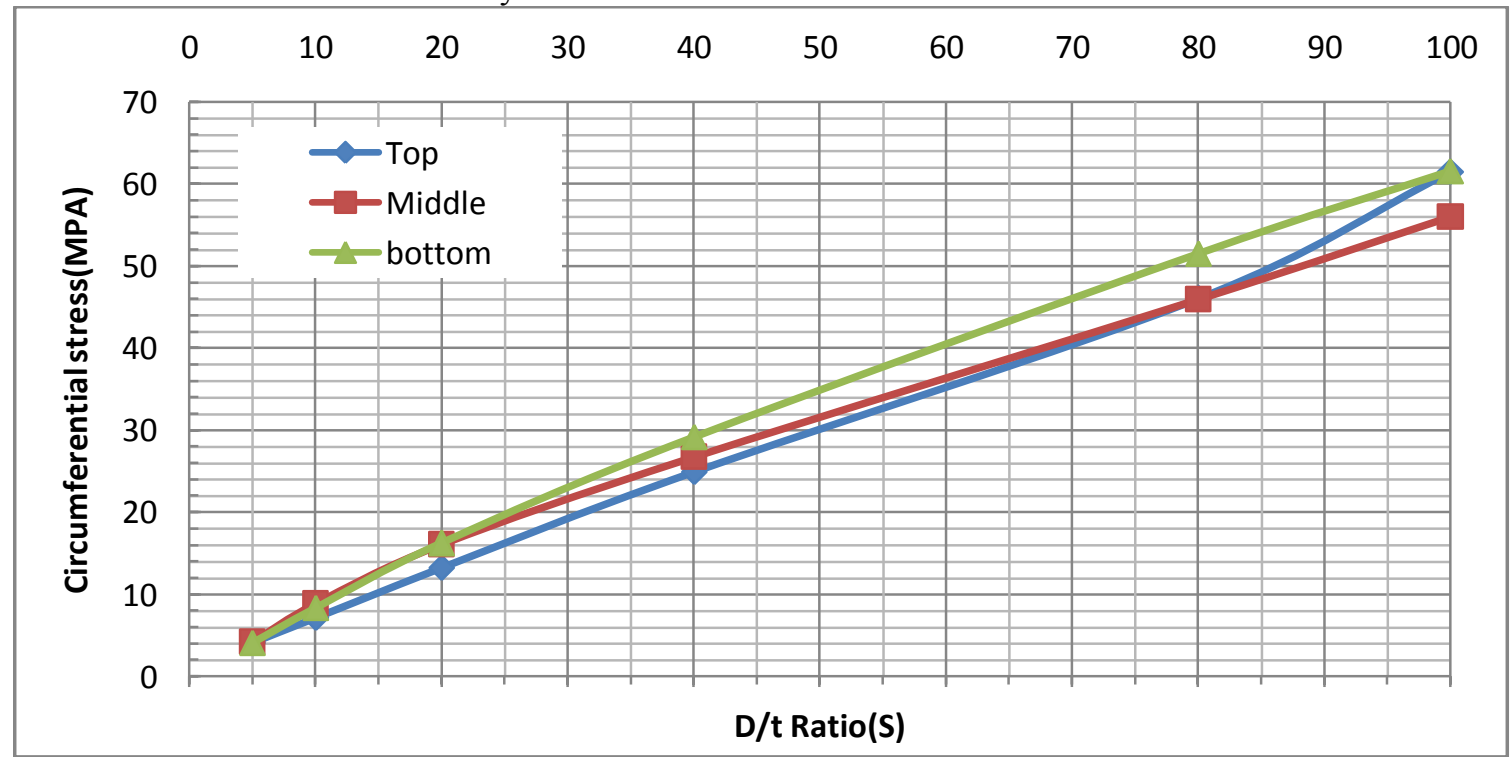

Fig 3. Variation of circumferential stress with respect to D/t Ratio(S) 


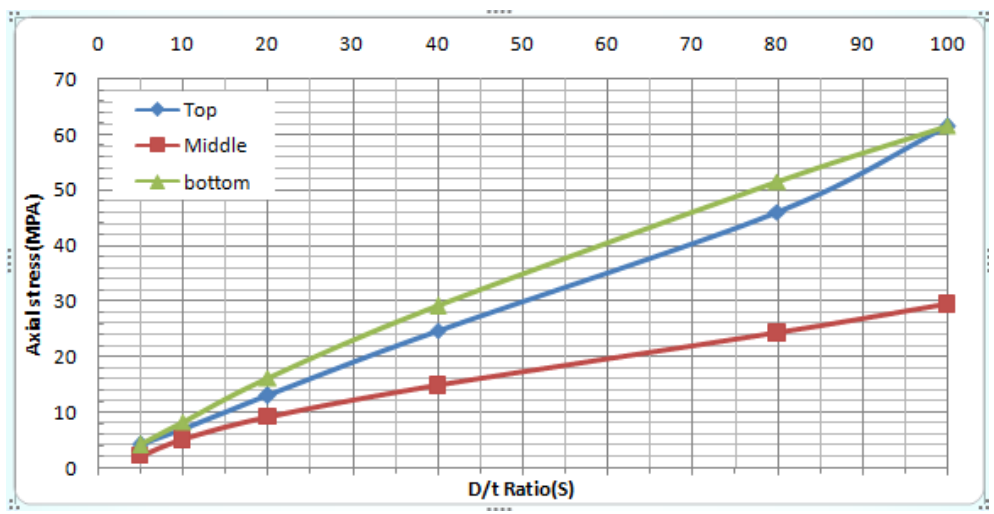

Fig 4. Variation of Axial stress with respect to D/t Ratio(S)

The variation of axial stress is shown with respect to $\mathrm{D} / \mathrm{t}$ ratio is as shown in fig 4 . It is observed that axial stress increases linearly in all the three portions with increase in the $\mathrm{d} / \mathrm{t}$ ratio. Compared with middle portion in end portions stress increment is maximum due to curvature in geometry. The maximum stress obtained in the top and bottom end portion is equal to 61MPA.

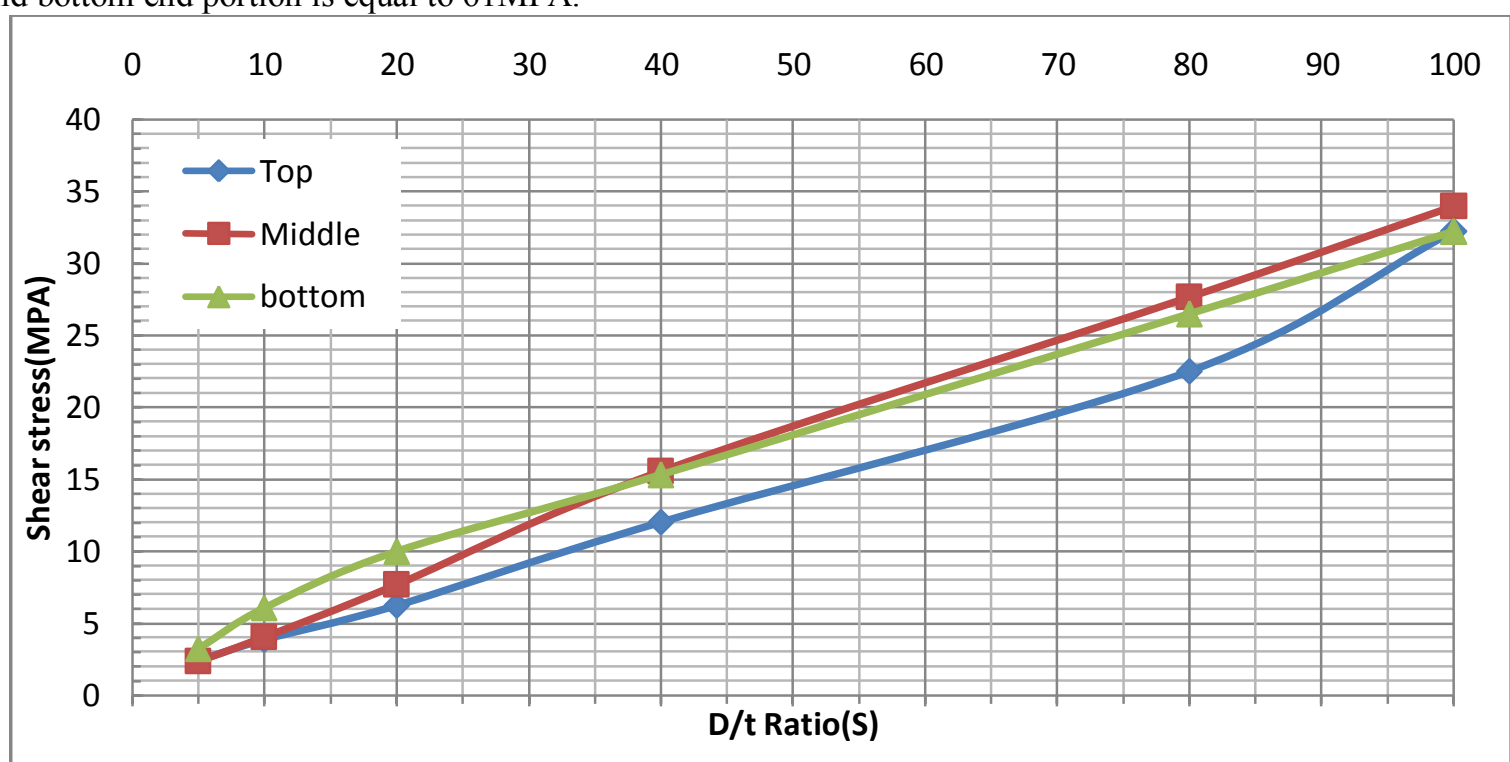

Fig 5.Variation of Shear Stress with respect to D/t Ratio.

It is observed that the shear stress $\left(\tau_{\theta z}\right)$ goes on increasing with an increase in $d / t$ ratio. All the three portions exhibit the same kind of behavior and the maximum value of stress at the $\mathrm{d} / \mathrm{t}$ ratio of 100 is $32 \mathrm{MPA}$.

\section{Effect of Fiber Angle}

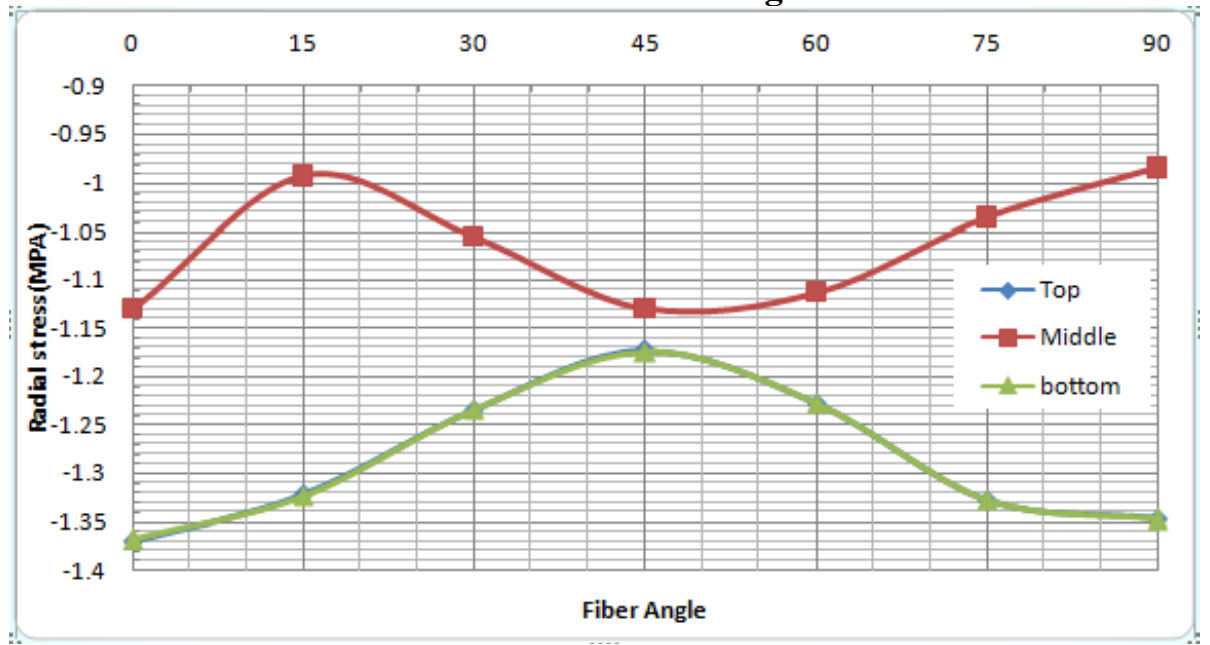

Fig 6. Variation of Radial stress with respect to Fiber Angle 
The variation of radial stress with respect to fiber angle is as shown in fig 6. For themiddle portionthe critical portion where the maximum stress occurs are $15^{\circ}$ fiber angle and $90^{\circ}$ fiber angle. For the ends the maximum stress occurs at $45^{\circ}$ fiber angle and hence it is considered as critical angle for the radial stress at ends. However the maximum value of stress $1.2 \mathrm{MPA}$ occurs at ends compared to middle portion. So $45^{\circ}$ is considered as safe fiber angle for both middle and end portions

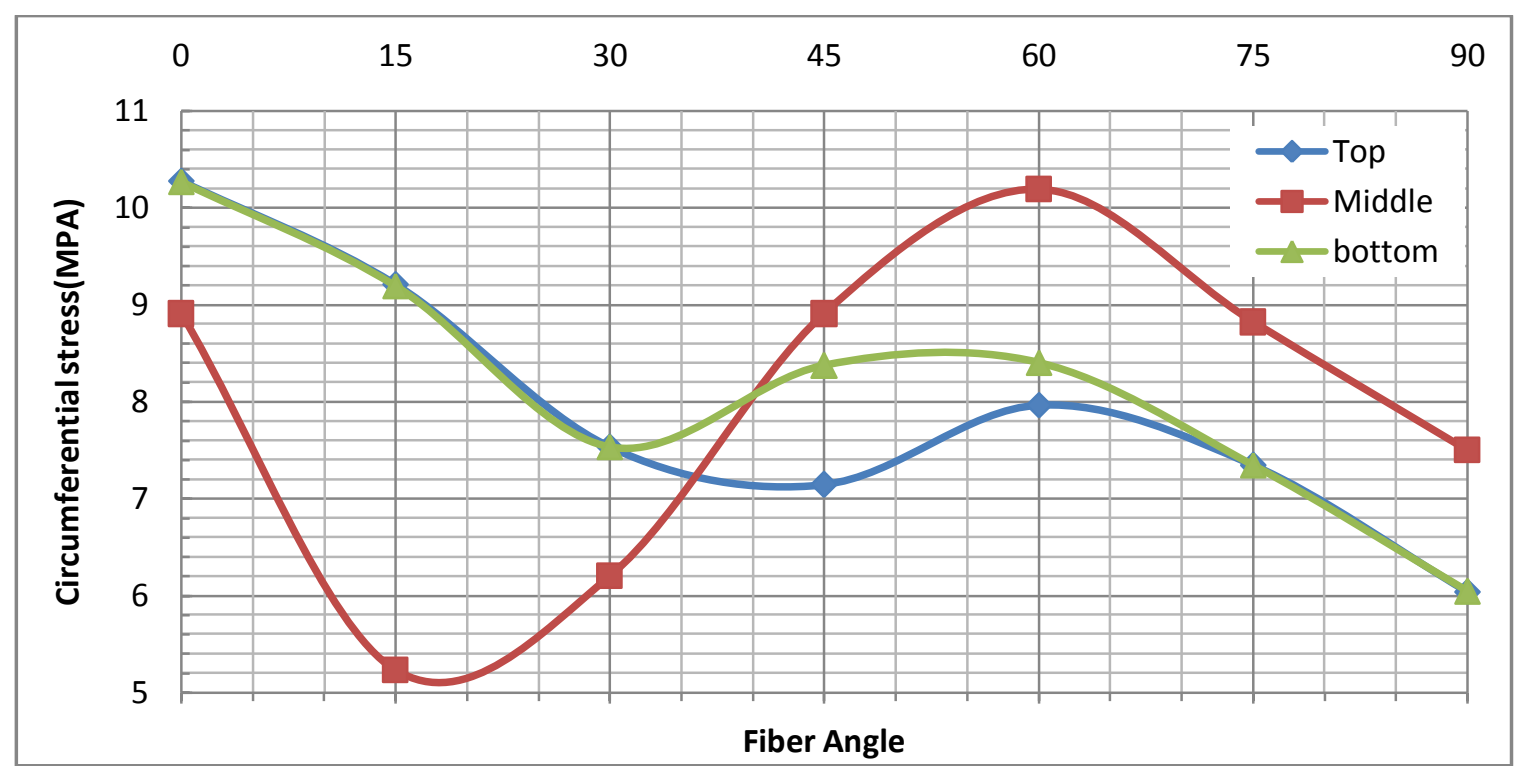

Fig 7. Variation of circumferential stress with respect to Fiber Angle

The variation of circumferential stress with respect to fiber angle is as shown in fig 7. It is observed that $60^{\circ}$ is the critical angle for middle portion as the maximum amount of stress 10.2 MPA occurs here. At the ends the maximum stress predicted is $11 \mathrm{MPA}$. So below $45^{\circ}$ fiber angle end portion will be considered as critical section. In the case of above $45^{\circ}$ fiber angle middleportion will be the critical section due to high stress.

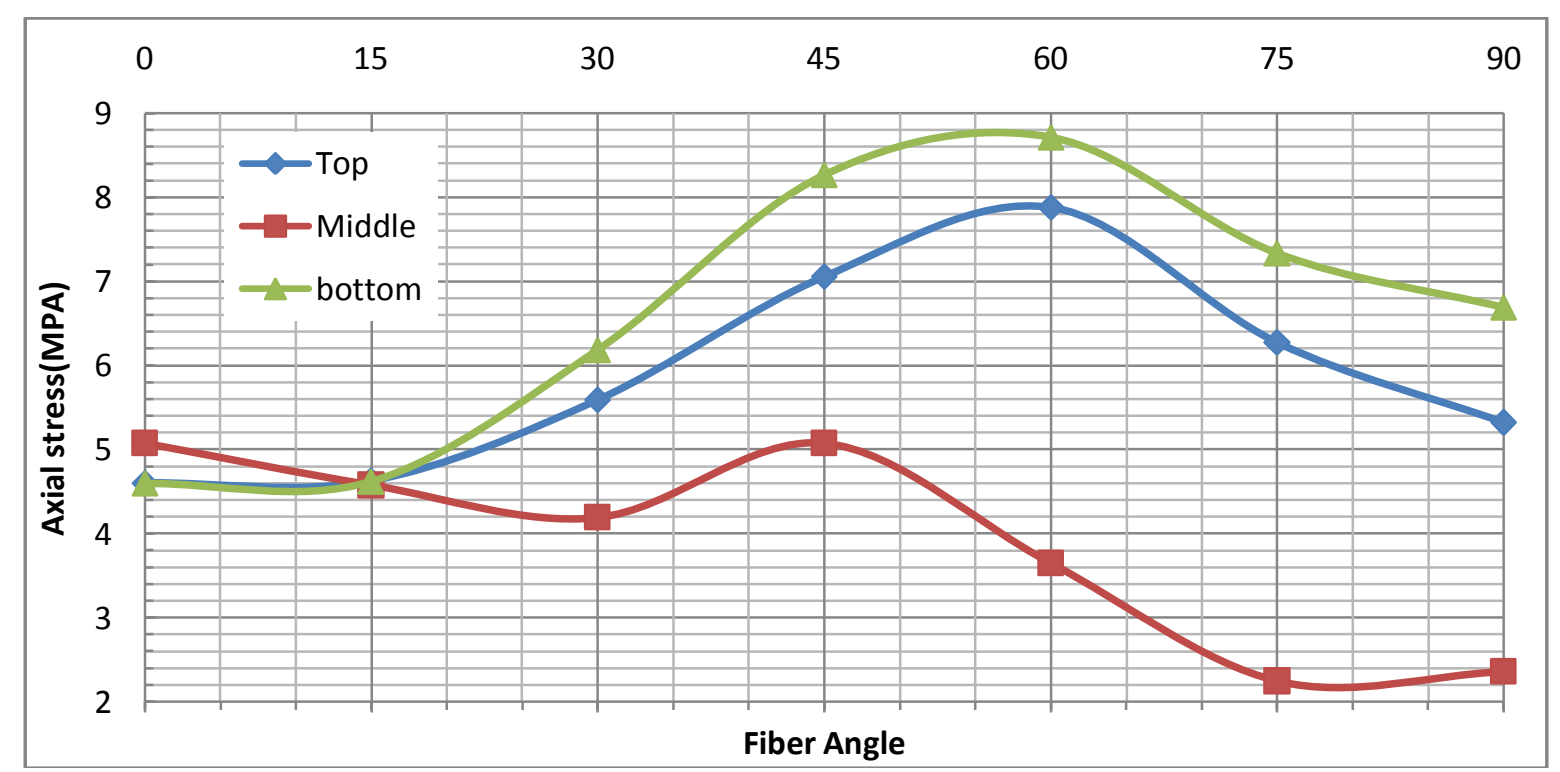

Fig 8 Variation of Axial stress with respect to Fiber Angle

The variation of axial stress with respect to fiber angle is as shown in fig 8. It is observed that all the three portions have uniform stressup to $15^{\circ}$ fiber angle.In middleportion maximum stress occurs at $45^{\circ}$ fiber angle. For the end portions maximum stress occurs at $60^{\circ}$ fiber angle. This is due to high resistance offered against axial deformation at this fiber angle. So $45^{\circ}$ to $60^{\circ}$ will be treated as critical fiber angles. 


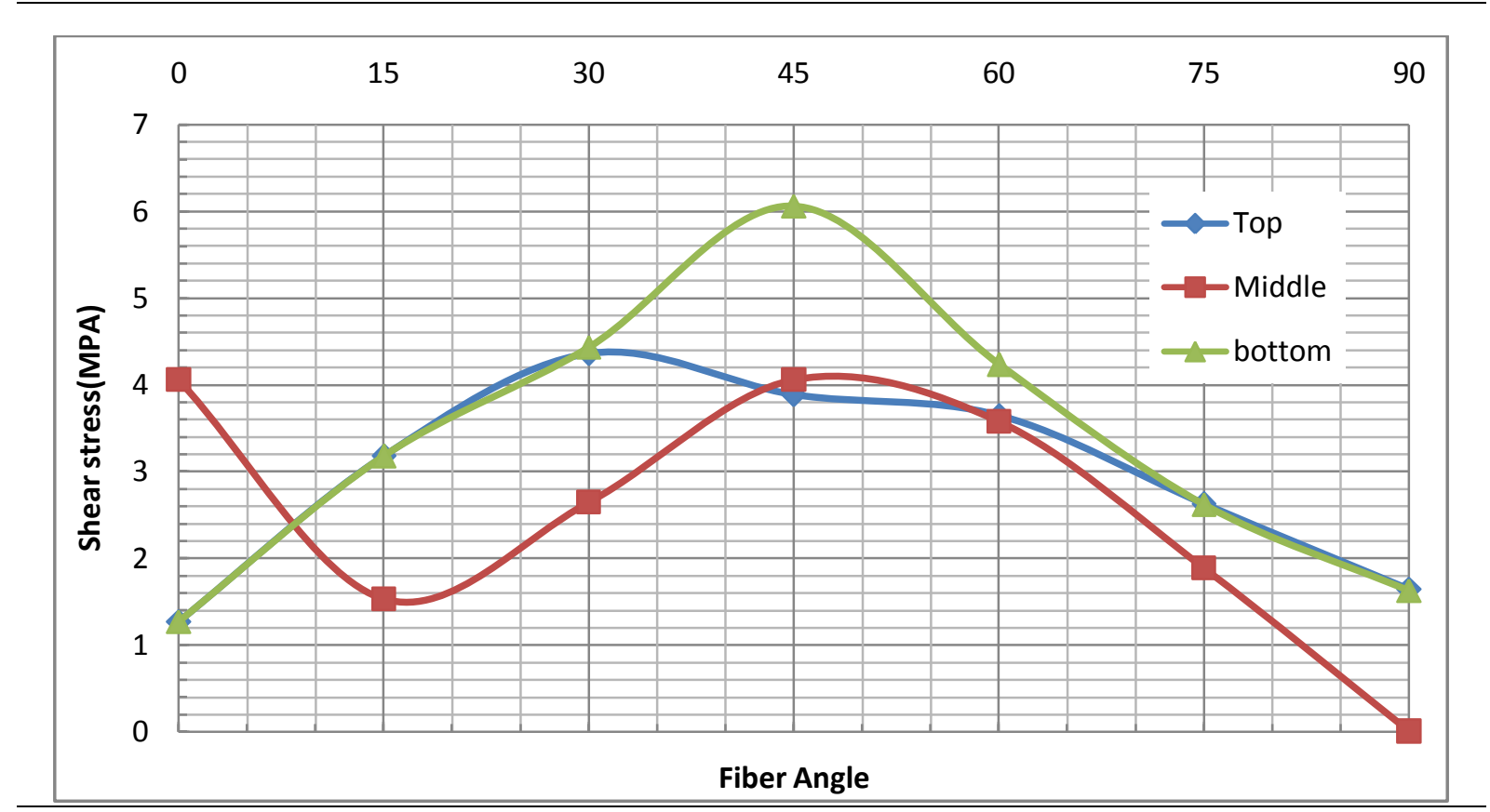

Fig 9 Variation of Shear stress with respect to Fiber Angle

The variation of shear stress $\left(\tau_{\theta z}\right)$ with respect to fiber angle is shown in fig 9. The maximum stress obtained in all portions at of $45^{\circ}$ fiber angle. This is dueto high resistance offered against pressure loading in axial and circumferential direction. Therefore $45^{\circ}$ is the critical fiber angle which influences shear stress for all the three portions.

\section{Conclusions}

A FRP composite cylinder with closed ends consisting of four layers is analyzed in the present work. Variation of stresses with respect to diameter to thickness (S) ratio and fiber angle have been presented. The stresses are increased with respect to diameter to thickness ratio due to reduction in thickness of the layer.Similar behavior is observed for middle and end potions. In the case of variation of stresses with respect to fiber angle, ends behave differently compared to middle portions. From the results it is concluded that the critical fiber angle is $45^{\circ}$ to $60^{\circ}$ as it offers high resistance against axial and circumferential deformation in middle and end portions.

\section{References}

[1] S. Adali, Verijenko and V. E. et al, "Optimization of multilayered composite pressure vessels using exact elasticity solution", Composites for the pressure vessels Industry, PVP-V302, ASME, 1995, pp.203-312.

[2] S. W. Tsai and A. K. Roy, "Design of thick composite cylinders", Journal of Pressure Vessel Technology, 1988.

[3] J. Michael Starbuck, "Stress analysis of laminated composite cylinders under non-axisymmetric loading", Lockheed Martin Energy Research Corporation, DE-ACO5-960R22464.

[4] O. Sayman, "Analysis of multi-layered composite cylinder under hygrothermal loading”, Composites part a, 2005, pp.1-11

[5] ChristosC.Chamis, Pascalk.Gotsis andLevonMinnetyan, "ProgressiveFractureandDamageToleranceofCompositePressureVessels".

[6] M. T. Ahmadian and M. Bonakdar, "A new cylindrical element formulation and its application to structural analysis of laminated hollow cylinders", Finite Elements in Analysis and Design 44, 2008, pp. 617-630.

[7] V. Kranthi Kumar, K. Ravi Kumar, V. Bala Krishna Murthy, "Stress analysis of six layered FRP composite cylinder", International Journal of Applied Engineering Research, Volume 6, Number 19, 2011, pp. 2243-2250.

[8] E.V. Morozov, M. Hoarau and K. E. Morozov, "Filament winding patterns and stress analysis of thin walled composite cylinders", North Carolina State University, 2003.

[9] Rani Fayez El-Haj jar "Experimental study and analytical modeling of trans layer fracture in pultruded FRP composites", Doctor of Philosophy in the school of civil and Environmental engineering, Georgia institute of Technology, May 2004.

[10] S. Bhavya, P. Ravi Kumar, Sd. Abdul Kalam, "Failure Analysis of a Composite Cylinder", IOSR Journal of Mechanical and Civil Engineering, Volume Number 3, pp. 01-07

[11] J.C. Velosa, J. P. Nunes, P.J. Antunes, J. F. Silva "Development of a new generation of filament wound composite pressure cylinders", Ciencia e Tecnologia dos Materials, Vol. 19, 2007. 